\title{
Unicentric Castleman's Disease Presenting as Retroperitoneal Pelvic Lymph Node in Young Female-Laparoscopic Excision: A Case Report
}

\author{
Divyesh V. Shukla*, Shilpi D. Shukla, Amit Shah, Sangita Patel, Salome Shukla \\ Isha Hospital, Sarabhai Campus, Vadodara, India \\ Email: *divyeshshukla@yahoo.com
}

How to cite this paper: Shukla, D.V., Shukla, S.D., Shah, A., Patel, S. and Shukla, S. (2020) Unicentric Castleman's Disease Presenting as Retroperitoneal Pelvic Lymph Node in Young Female-Laparoscopic Excision: A Case Report. Open Journal of Obstetrics and Gynecology, 10, 1590-1608. https://doi.org/10.4236/ojog.2020.10110143

Received: September 19, 2020

Accepted: November 15, 2020

Published: November 18, 2020

Copyright $\odot 2020$ by author(s) and Scientific Research Publishing Inc. This work is licensed under the Creative Commons Attribution International License (CC BY 4.0).

http://creativecommons.org/licenses/by/4.0/

(c) (i) Open Access

\begin{abstract}
Unicentric Castleman's disease (UCD) is localized lymphoproliferative disease and has favourable prognosis. Surgery offers complete cure of unicentric Castleman disease. Radiotherapy offers either complete response or variable clinical response and cure in selected patients. The present case report is of a young unmarried obese girl presented with pain in right iliac fossa for 2 months. On pelvic ultrasound and MRI performed for diagnosis only single enlarged right external iliac lymph node was the positive finding. The CT scan guided biopsy was performed and the histopathological finding was lymphoid lesion-reactive lymphoid hyperplasia is favoured over Hodgkin's lymphoma. Successful laparoscopic complete excisional surgery was performed for this single enlarged external iliac lymph node. The final histopathological report of the lymph node removed was unicentric Castleman's disease, hyaline vascular type. This is the 16th such reported case of pelvic retroperitoneal UCD of hyaline vascular type treated by surgical excision, and 3rd case treated by Laparoscopic excisional surgery. By now at the time of reporting this case 4 months of follow up has been completed and patient does not have any symptom nor not show any sign of residual disease locally on transabdominal ultrasound examination and whole-body PET CT scan is also normal.
\end{abstract}

\section{Keywords}

Laparoscopic Surgery, Unicentric Castleman's Disease, Adnexal Mass

\section{Introduction}

Unicentric Castleman's disease (UCD) is localized lymphoproliferative disease and has favourable prognosis. Multicentric Castleman's disease (MCD) is more of a systemic disorder. IL-6 (interleukin 6) and HHV-8 (Human herpesvirus 8) 
have been implicated in pathogenesis of the disease. The disease is called as orphan disease as the incidence is 16 to $21-25 /$ million person years [1] [2]. UCD is more common than MCD. Surgery generally offers complete cure of disease.

\section{Case Report}

This is a case report of 24 yrs. Young unmarried obese female presented with lower abdominal pain and generalized weakness for 2 months.

Before being referred to us she was investigated at another hospital where MRI was performed. The report of MRI was uterus and both adnexal structures were normal, a lobulated solid lesion in right iliac fossa of $73 \times 49 \times 35 \mathrm{~mm}$, regular well circumscribed with areas of calcification without necrosis within suspicion of soft tissue neoplastic lesion (Figures 1-6).

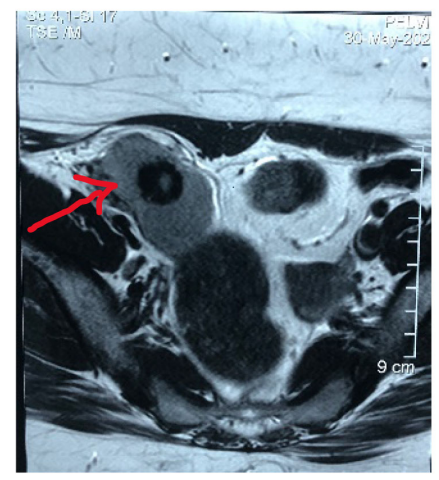

Figure 1. MRI T1 weighted image of the mass Coronal section.

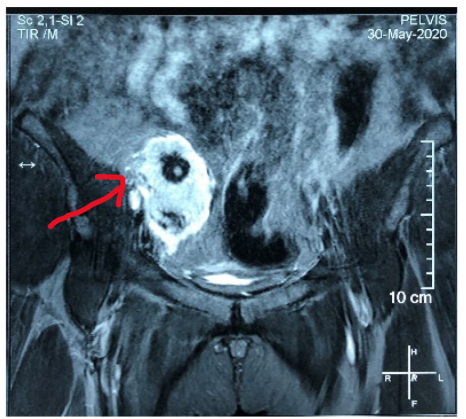

Figure 2. MRI T2 weighted image of the mass Coronal section 1.

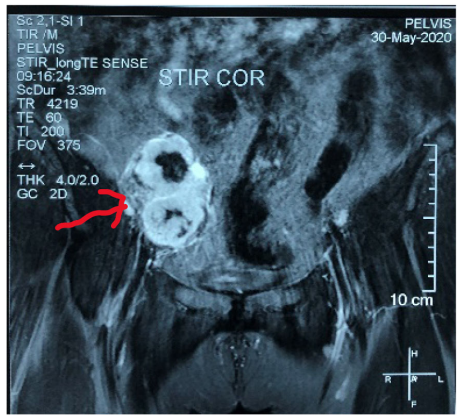

Figure 3. MRI T2 weighted image of the mass Coronal section 2. 


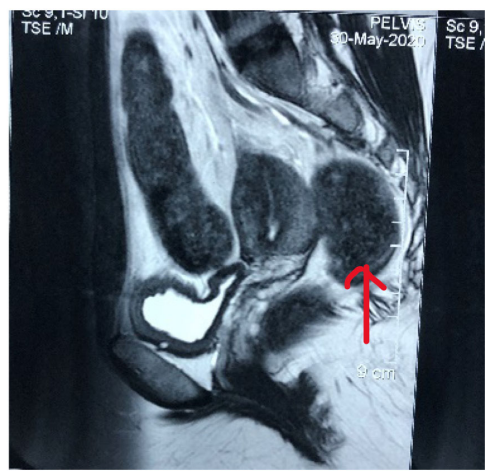

Figure 4. MRI T1 weighted image of the mass sagittal section.

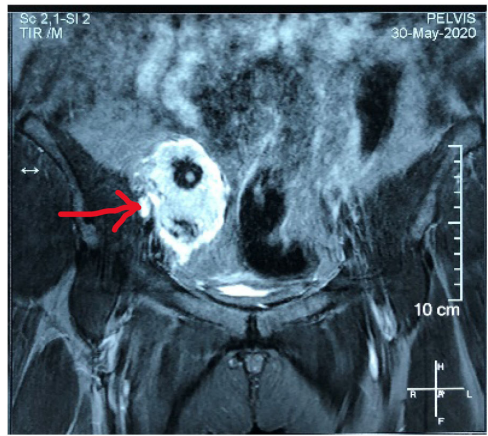

Figure 5. MRI T2 weighted image of the mass Coronal section 3.

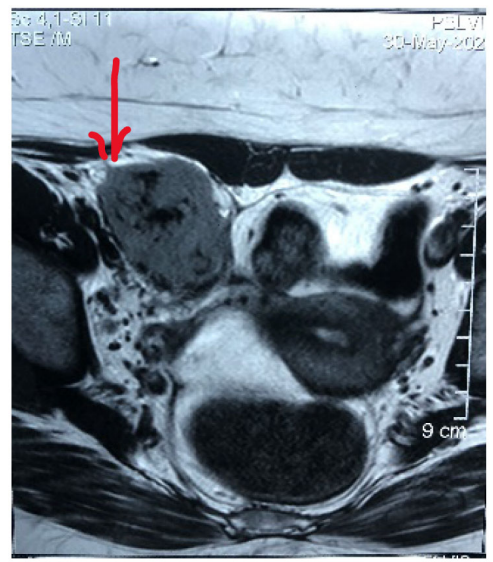

Figure 6. MRI T1 weighted image of mass, uterus, ovaries separate.

Based on MRI report CT guided biopsy was performed in the same hospital which reported as lymphoid lesion-reactive lymphoid hyperplasia is favoured over Hodgkin's lymphoma (Figure 7).

She was referred for laparoscopic excisional biopsy with a suspicion of lymphoid hyperplastic disease.

When she presented to us her vital signs were normal (Pulse: 90/min, B.P: 120/70 mmhg, $\mathrm{SpO}_{2}: 99 \%$ ) and had a BMI of 37. There were no symptoms related to bowel or bladder. On abdominal palpation she was obese and a firm tender fixed mass was palpable in right iliac fossa with ill-defined margins. We 


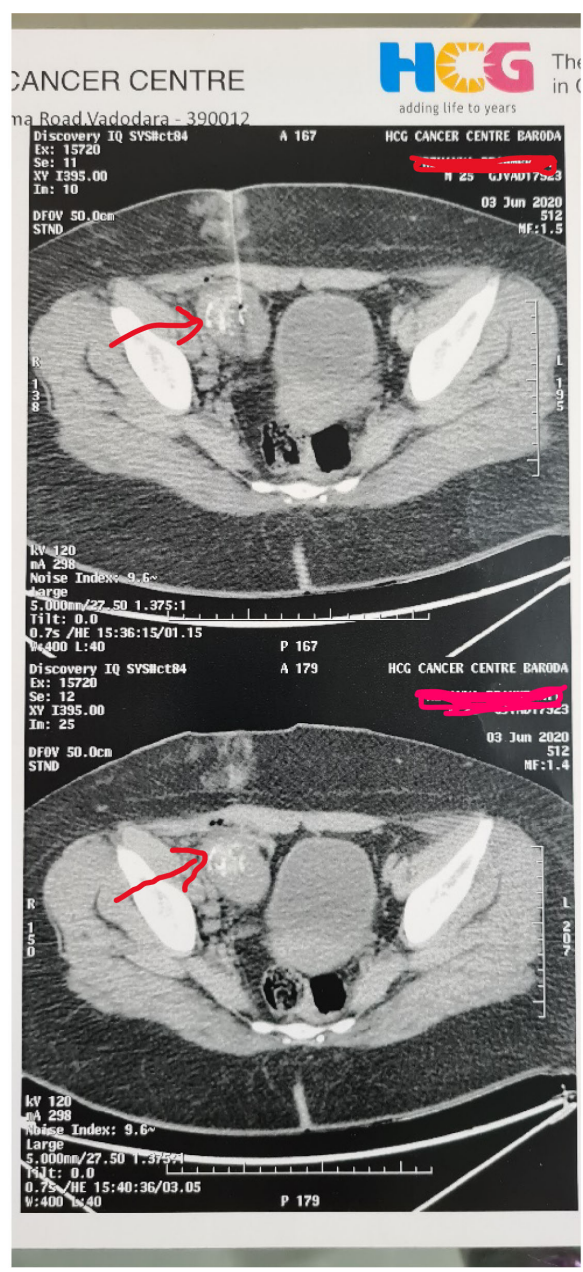

Figure 7. CT guided biopsy of mass.

had additionally performed transabdominal ultrasonography to see the characteristic of the mass. Uterus and both ovaries were normal. Right ovary was separately identified. Ultrasound scanning the palpable mass revealed about $75 \times 48$ $\mathrm{mm}$ echogenic mass with evident vascularity around the periphery with hypoechoic central area with distinct margins. Areas of calcification were seen below the surface anteriorly. The mass was positioned over external iliac vessels at internal inguinal ring. The RI of color doppler flow was 0.6 and PSV of 45.81 $\mathrm{cm} / \mathrm{sec}$. It was concluded finally as enlarged external iliac group of lymph node (Figures 8-13).

Laparoscopic excisional biopsy was planned. Her pre-operative blood investigations were normal (Haemoglobin: 11.8 gms\%, TC: 12,270, Platelets: 411,000, Blood Group: B positive; SGPT: 26, S.Creatinine: 0.40, RBS: 143, Anti-HCV: non-reactive, Urine: NAD, HbA1C: 6.14, HIV: Negative; HbsAg: Negative, INR: 1.01, COVID-19 Negative, HHV-8 negative (post-operative). Chest X-ray and echocardiography also were normal.

Laparoscopic surgery was performed by primary trocar inserted $4 \mathrm{~cm}$ above umbilicus in midline and 3 ancillary trocars. About $7.5 \mathrm{~cm}$ retroperitoneal mass 


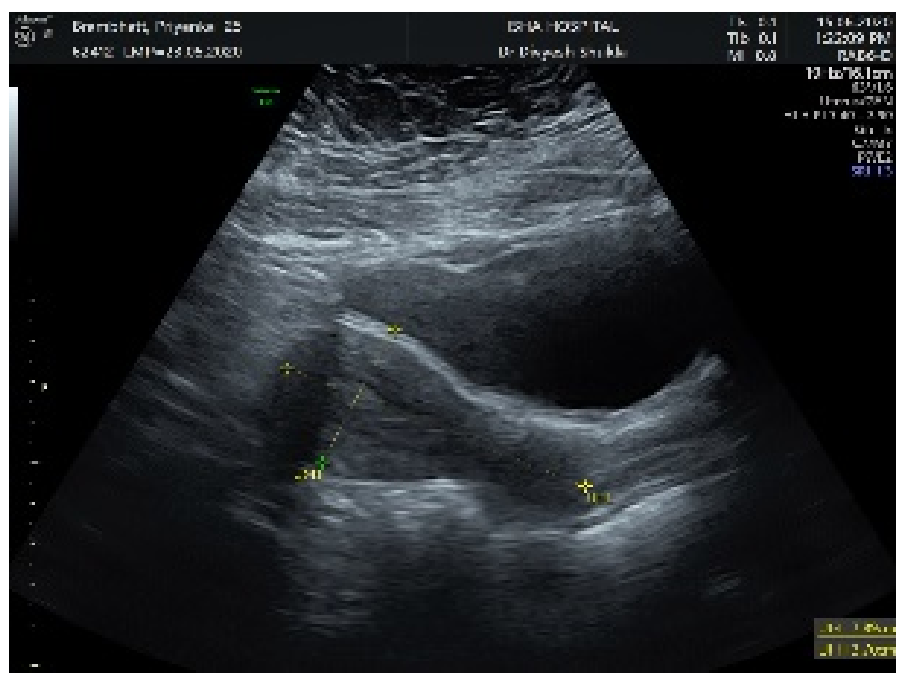

Figure 8. Transabdominal USG uterus.

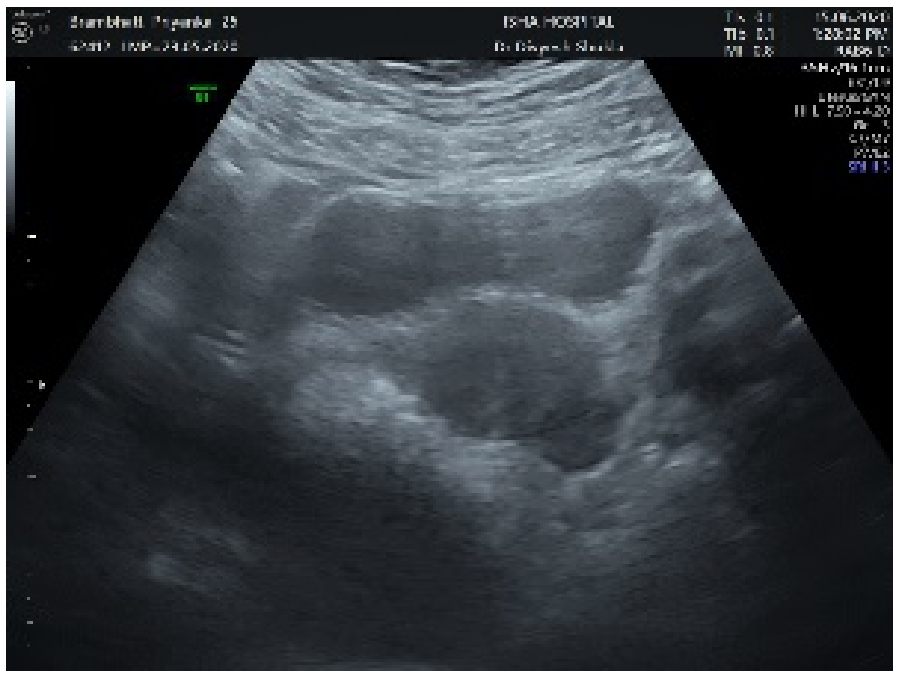

Figure 9. Transabdominal USG uterus with left ovary.

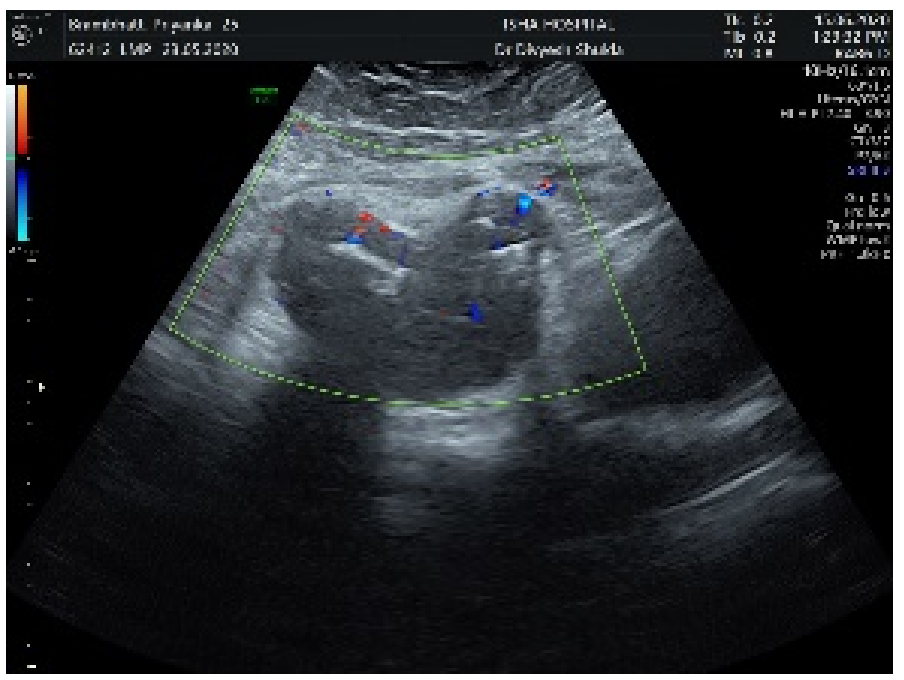

Figure 10. Transabdominal USG Lobulated mass with calcification. 


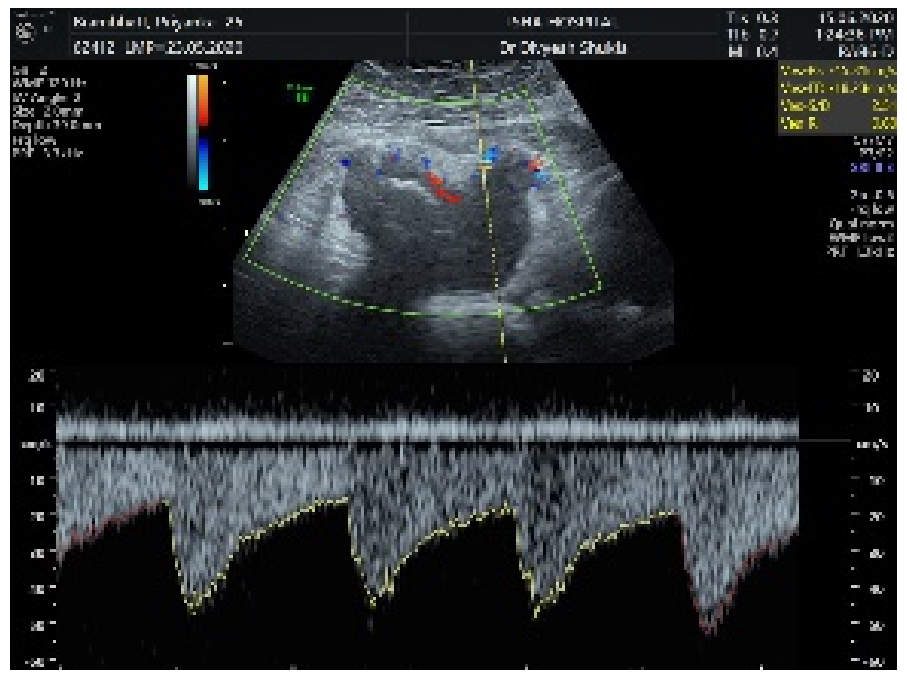

Figure 11. Transabdominal USG Lobulated mass PSV $45.81 \mathrm{~cm} / \mathrm{sec}$.

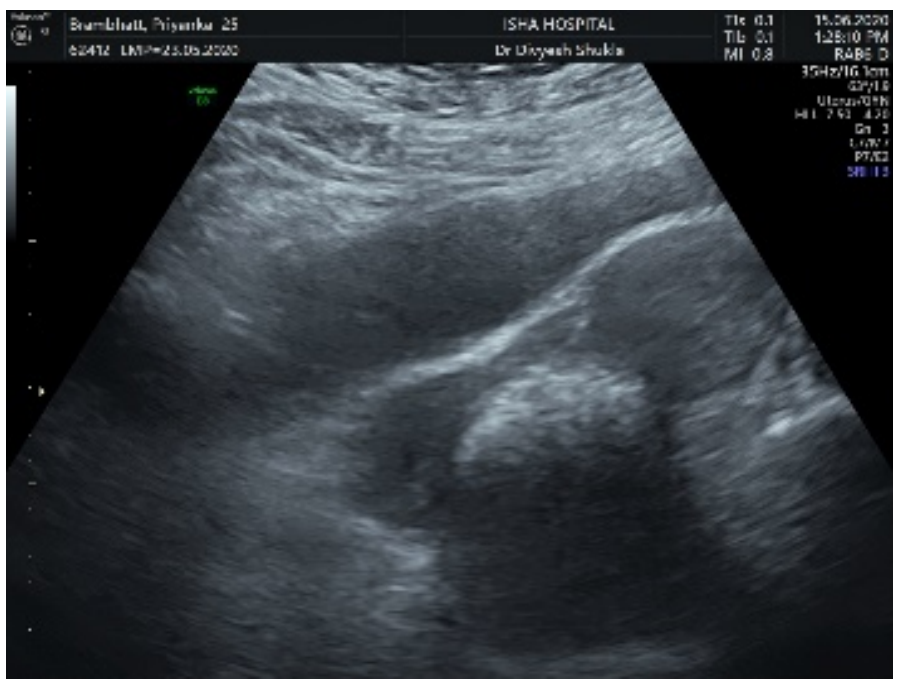

Figure 12. Transabdominal USG uterus with right ovary.

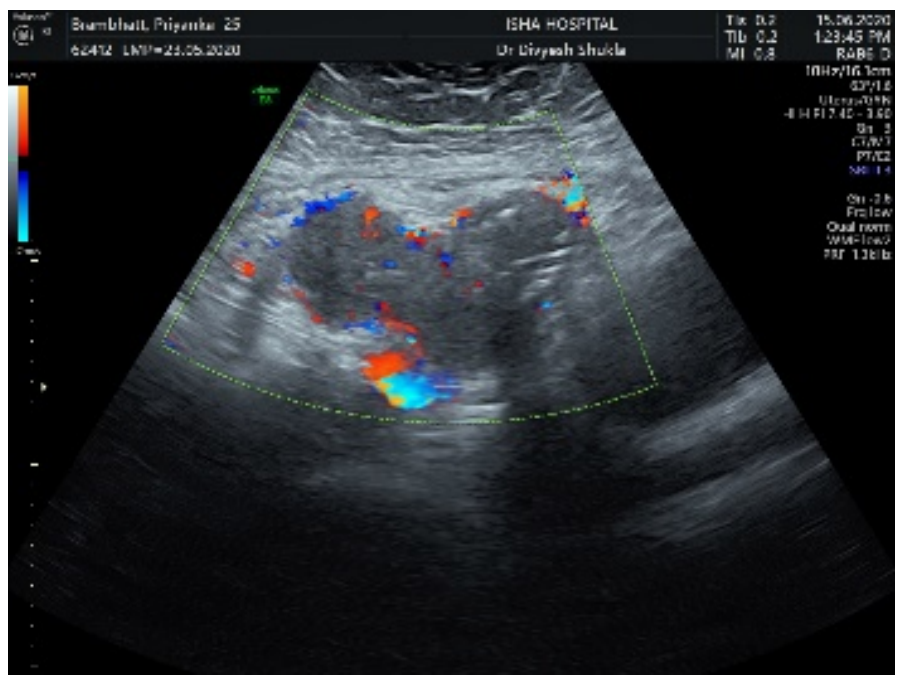

Figure 13. Transabdominal USG Lobulated mass with enhance peripheral vascularity. 
was seen in right iliac fossa near internal inguinal ring. Mass was over external iliac vessels extending upwards and was fixed to abdominal wall. Mass was extending anteriorly $3 \mathrm{~cm}$ beyond attachment of round ligament. Right round ligament was stretched above the mass. Peritoneum over the mass was cut, round ligament also was cut laterally for exposure. Covidien made Maryland Laparoscopic sealer/divider 1937 was used for dissection and haemostasis and complete surgical excision. Feeding vessels originated from external iliac artery. The attachment of mass to abdominal wall and inguinal ligament were dissected and cut. No attachment with external iliac vessels was seen. Capsule of the mass had remained intact during surgery and was a firm to hard in consistency. Mass was put in an appropriate size endobag. The bag was removed through left lower port incision which was extended to $3 \mathrm{~cm}$. The tissue was partially morcellated within the bag without spillage for its removal through small incision. The consistency of the mass was confirmed again as firm to hard while morcellating. Intraoperative blood loss was about $20 \mathrm{cc}$. There was no intra-operative complication. Left lower sheath was closed (Figures 14-27).

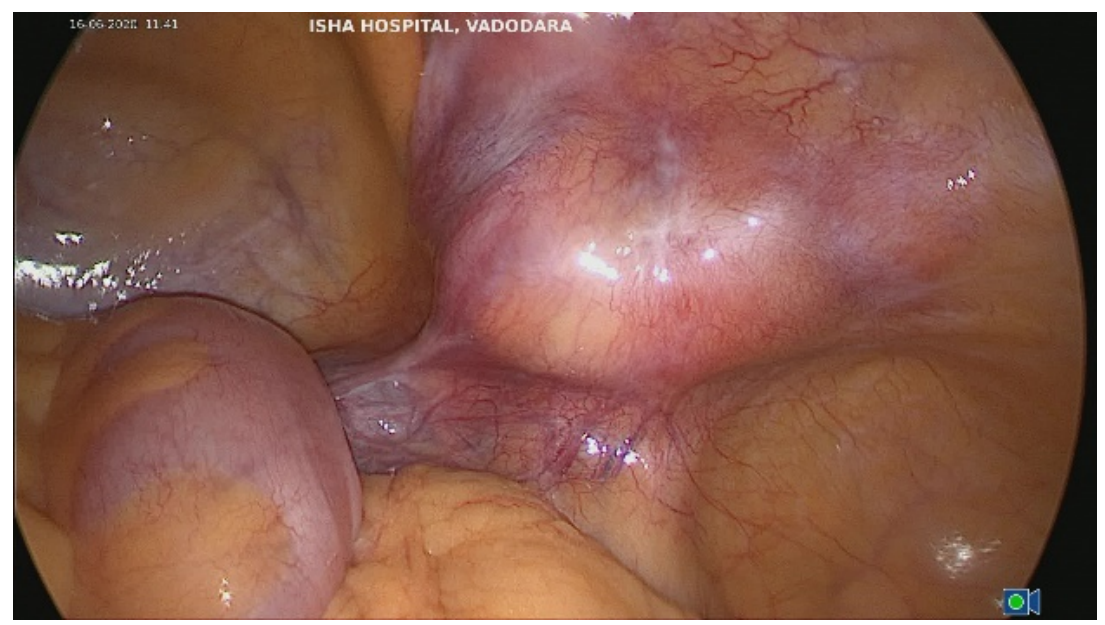

Figure 14. Mass in right iliac fossa.

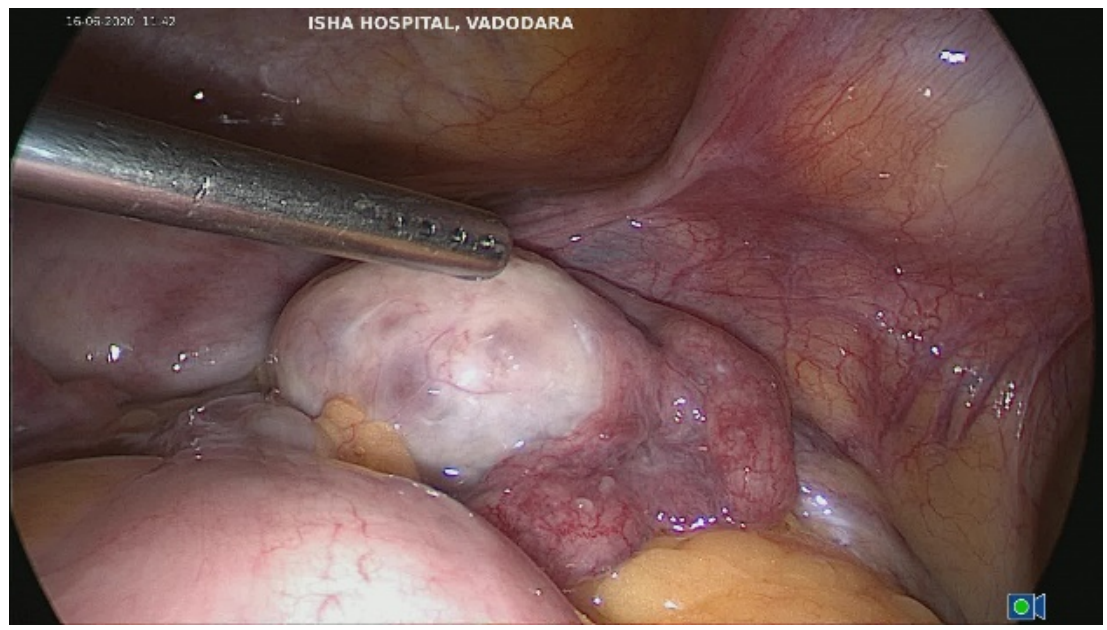

Figure 15. Mass in right iliac fossa, right ovary and tube seen. 


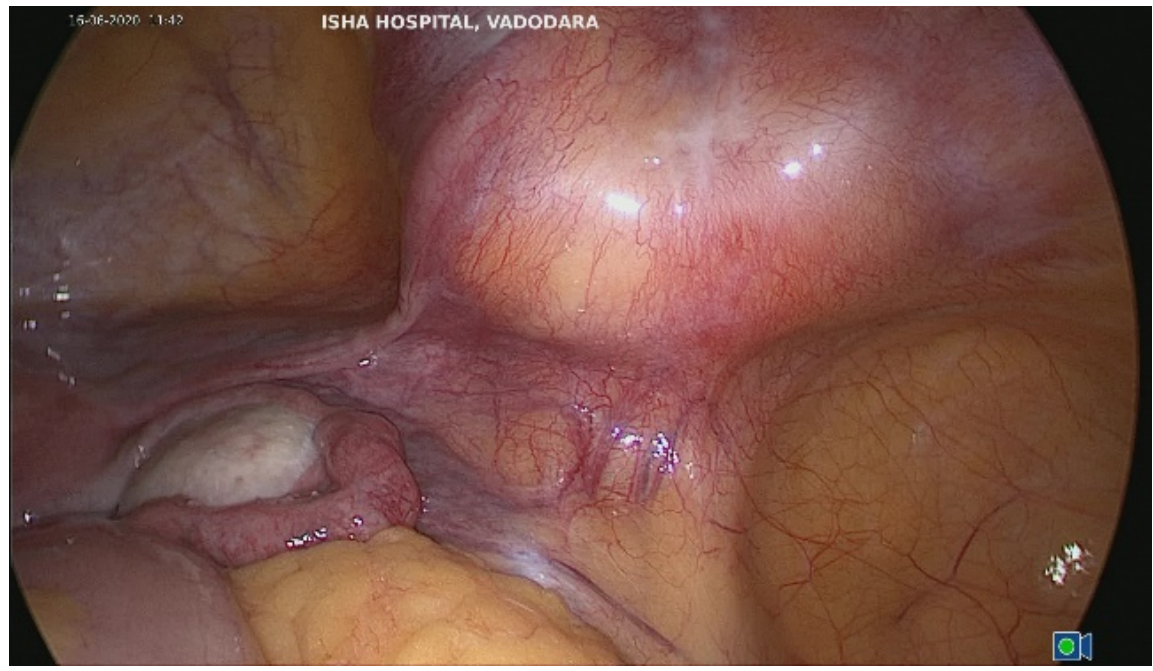

Figure 16. Mass with round ligament stretched.

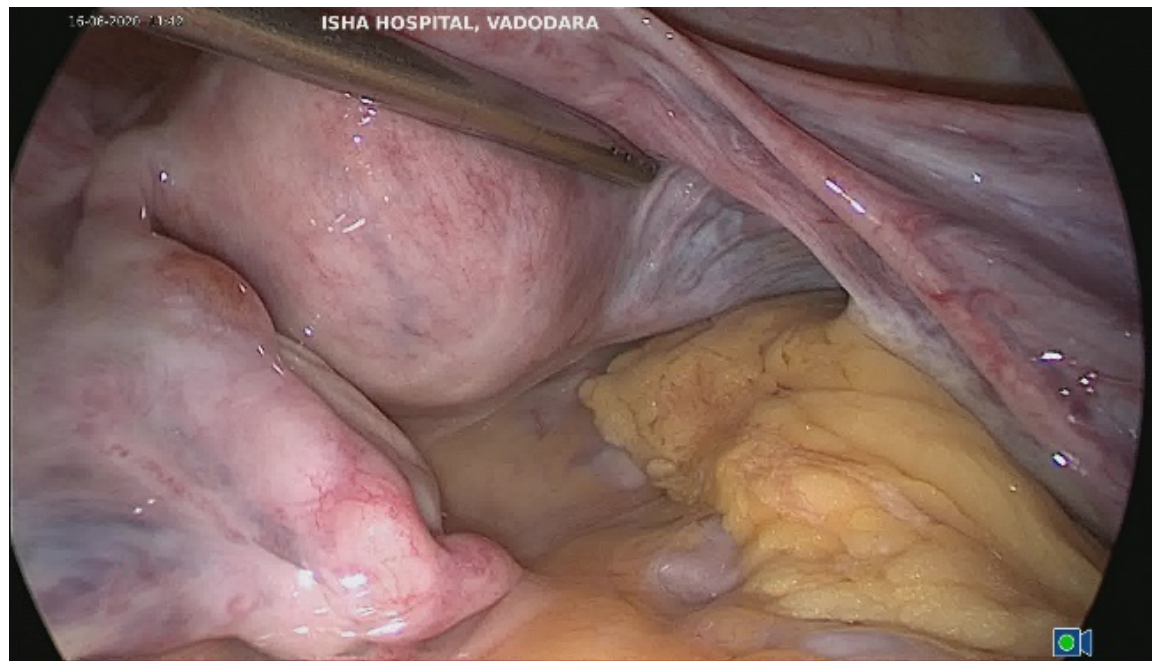

Figure 17. Normal uterus and both ovaries.

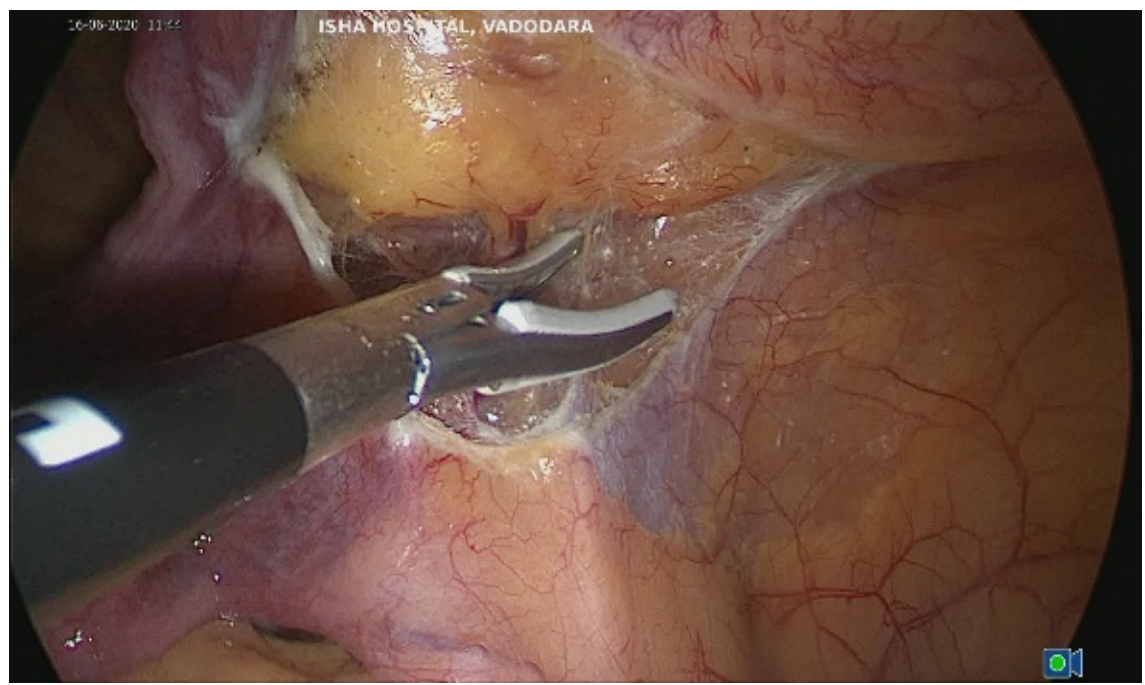

Figure 18. Surgery opening peritoneum. 


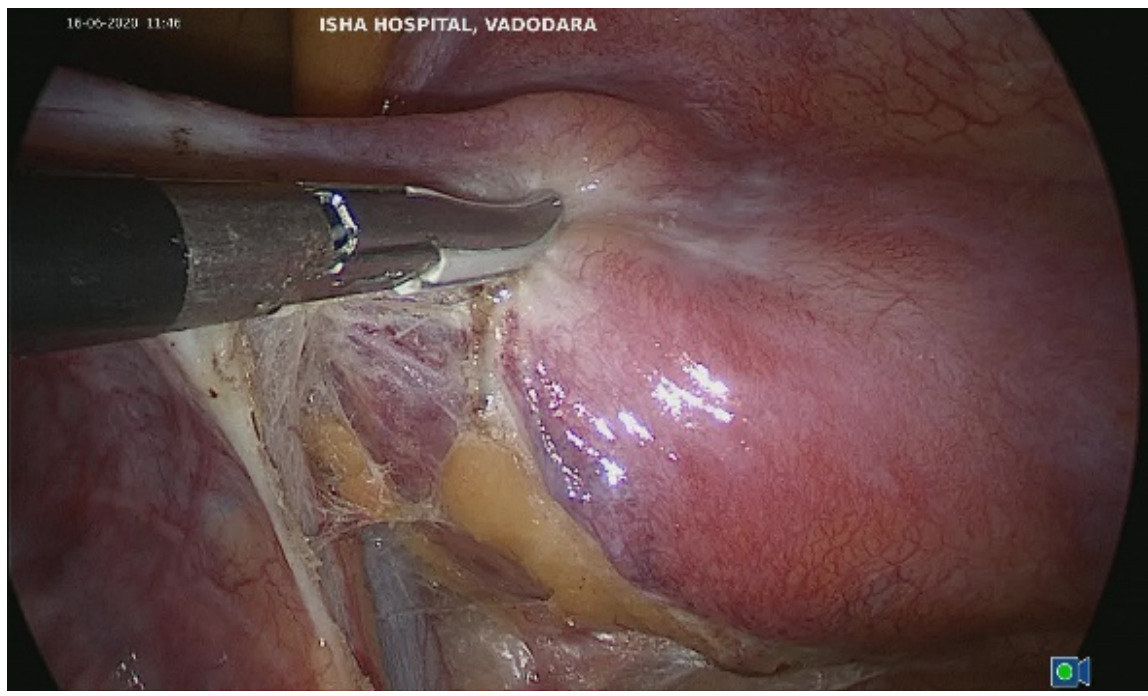

Figure 19. Surgery opening peritoneum cutting round ligament.

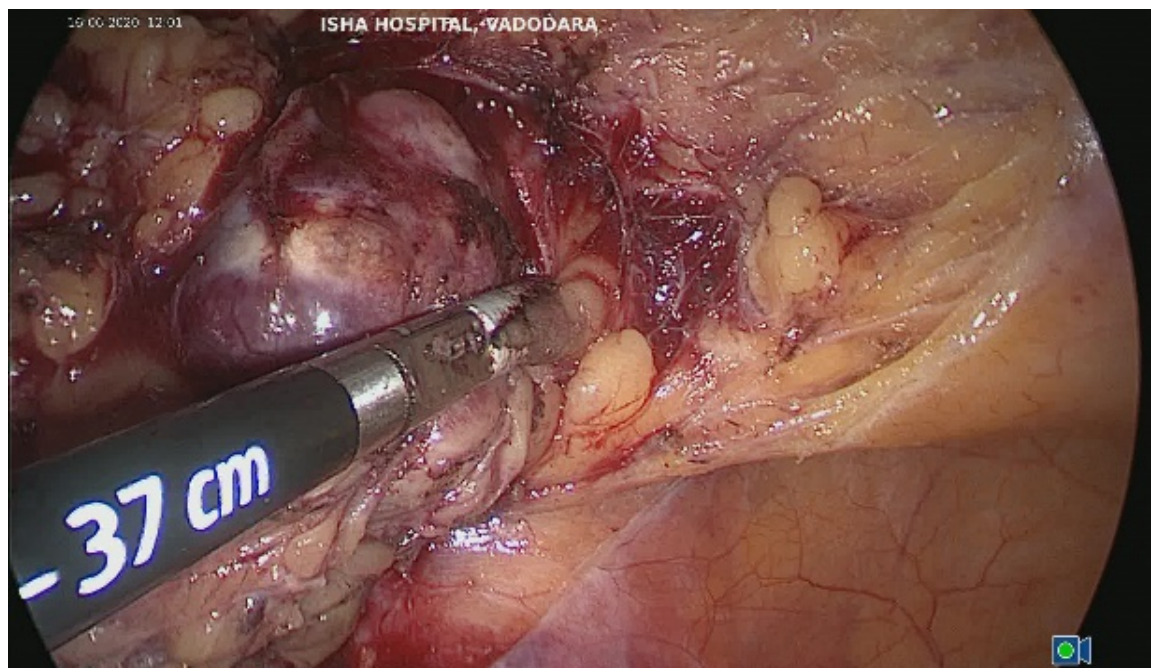

Figure 20. Surgery dissection of mass.

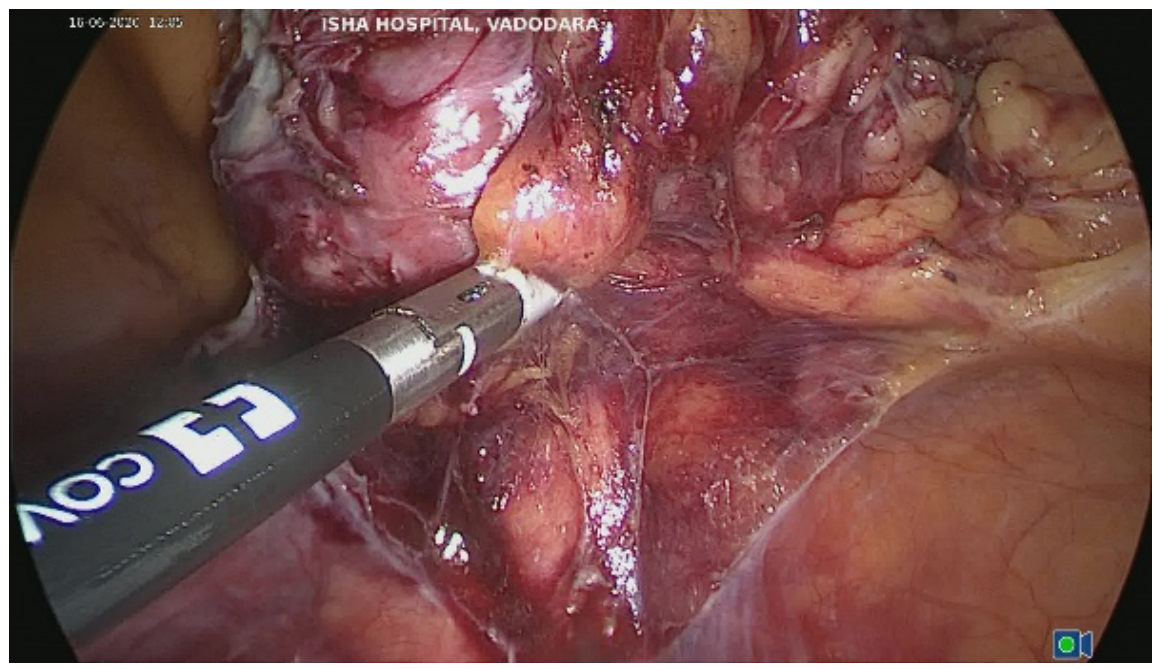

Figure 21. Surgery further dissection of mass. 


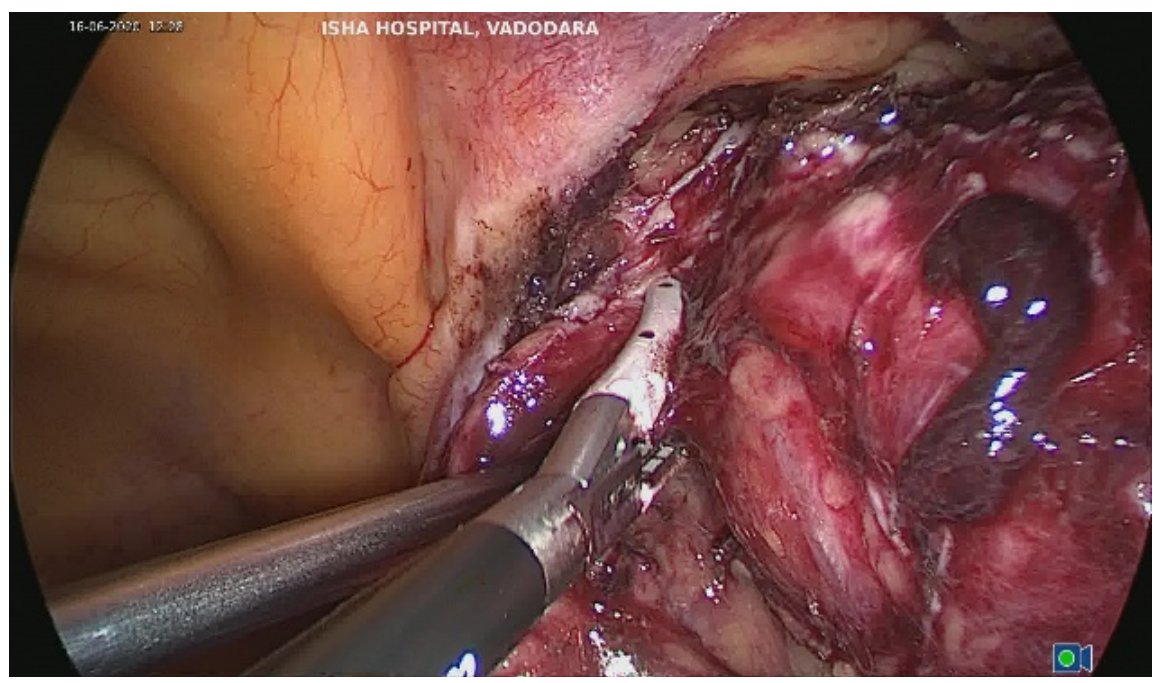

Figure 22. Surgery dissection of mass near complete dissection.

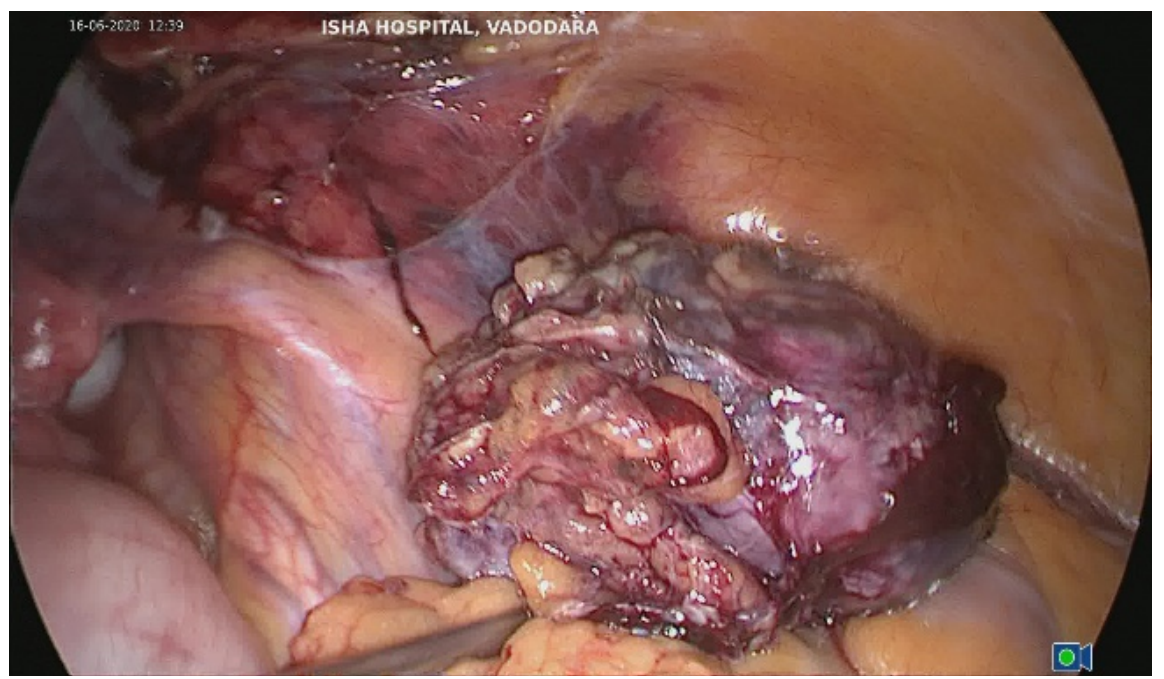

Figure 23. Surgery complete removal of mass.

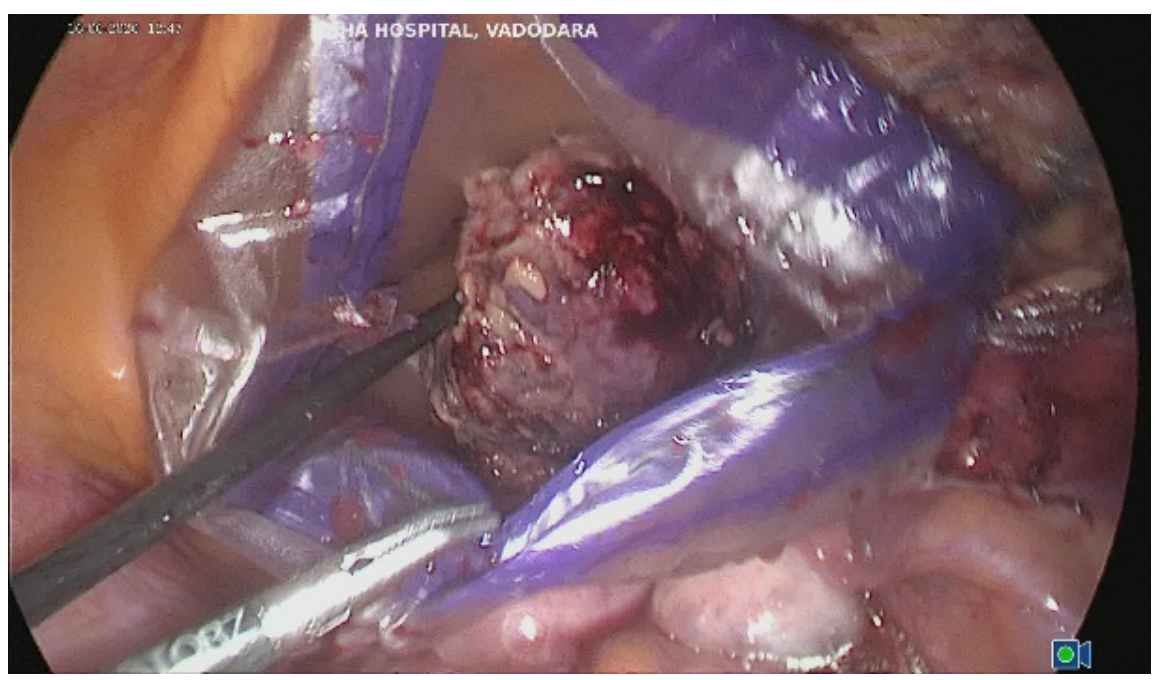

Figure 24. Surgery endobag removal of mass. 


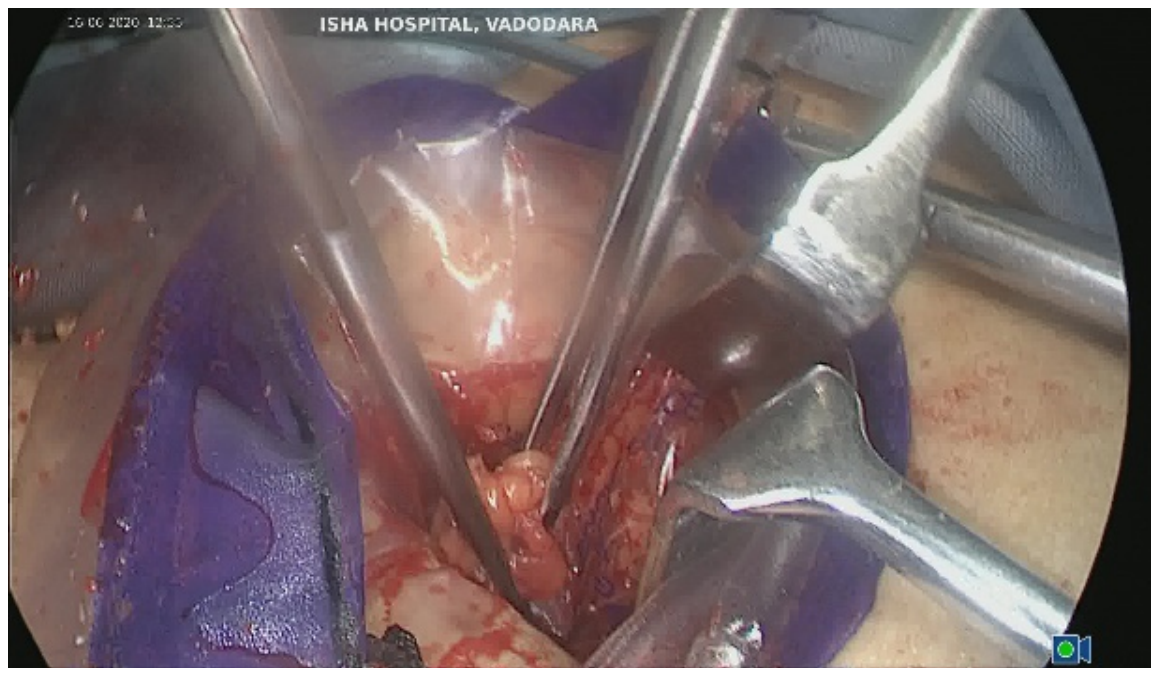

Figure 25. Surgery endobag removal of mass, partial morcellation within the bag.

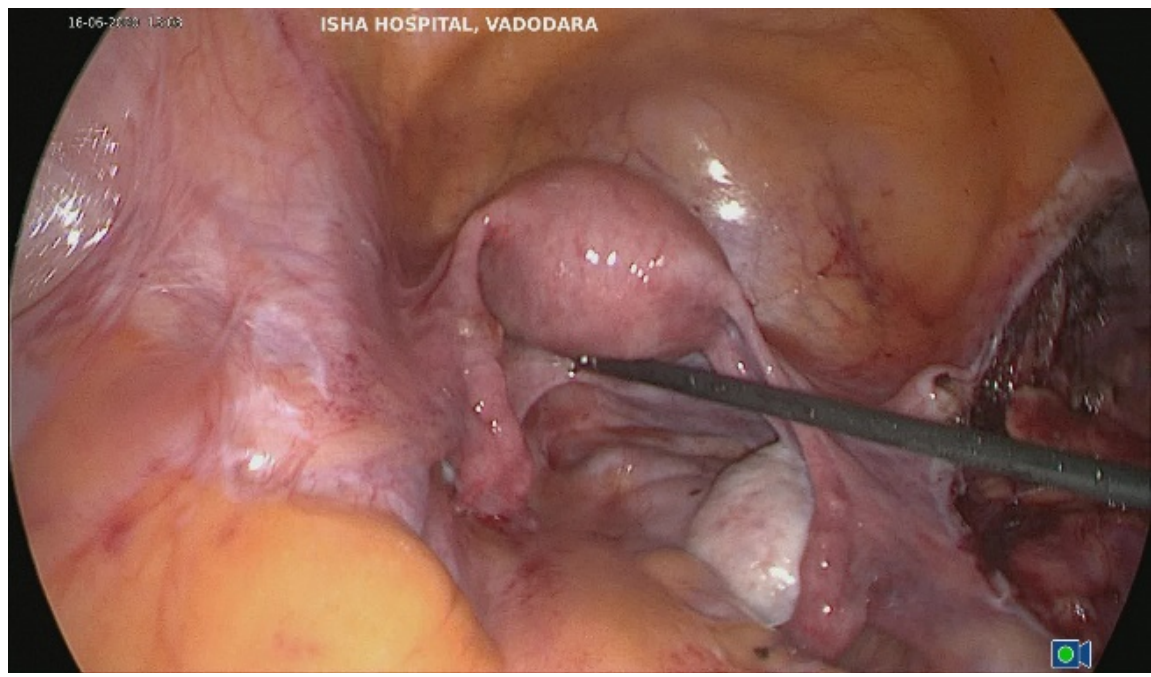

Figure 26. Surgery final result.

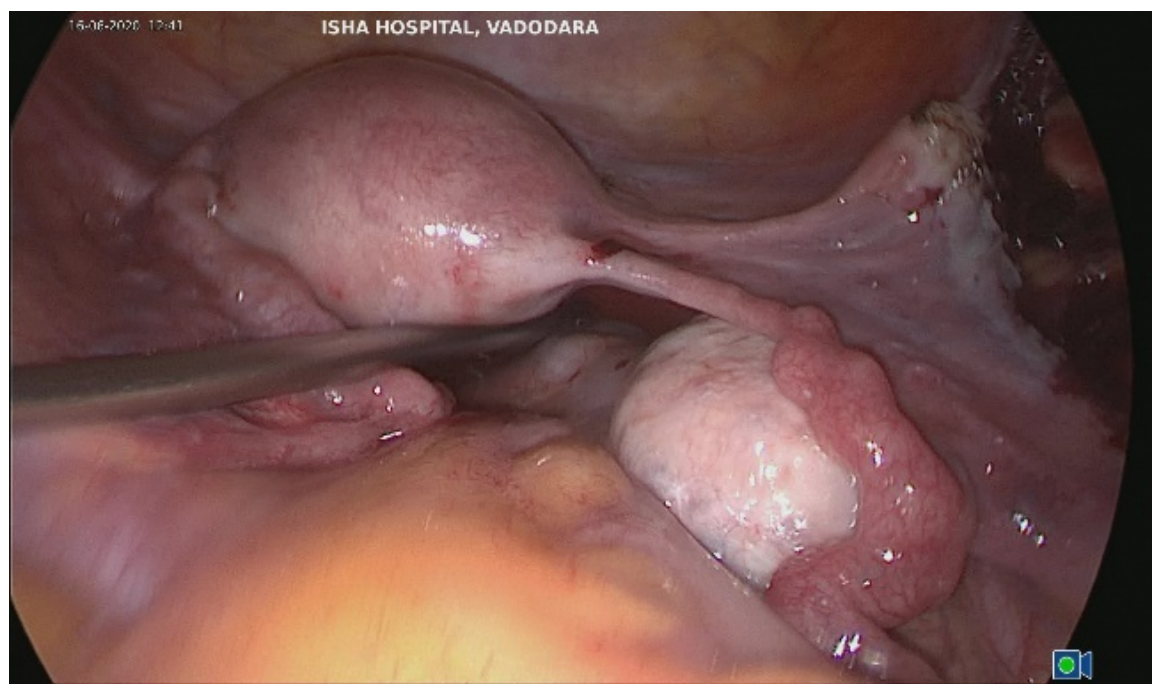

Figure 27. Surgery final magnified result. 
The histopathology report-The sections comprise of lymphoid parenchyma showing proliferation of lymphoid follicles of variable sizes and shapes throughout the node and broad mantle zones with small lymphocytes arranged in concentric manner around the germinal centers. The follicles show small hyalinized germinal centers, few show no germinal centers. Occasional large bizarre cells are seen in the follicles. At places, small vessels are seen penetrating the follicles. The interfollicular region shows increased numbers of high endothelial venules and small vessels with hyalinized walls. Plasmacytoid monocytes and plasma cells are also seen. Focal area of calcification is seen. Epithelioid granulomas, necrosis and, eosinophils are not seen. These appearances are those angio follicular lymphoid hyperplasia-Castleman's disease (Hyaline vascular type) (Figures 28-38).

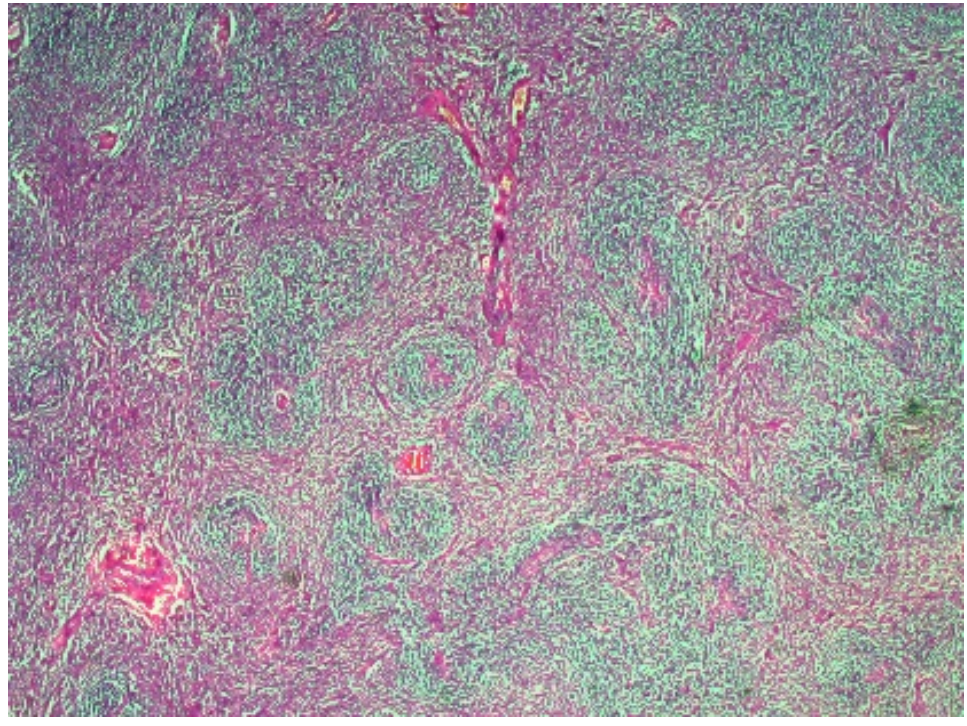

Figure 28. Histopathology $10 \times$ view of follicles.

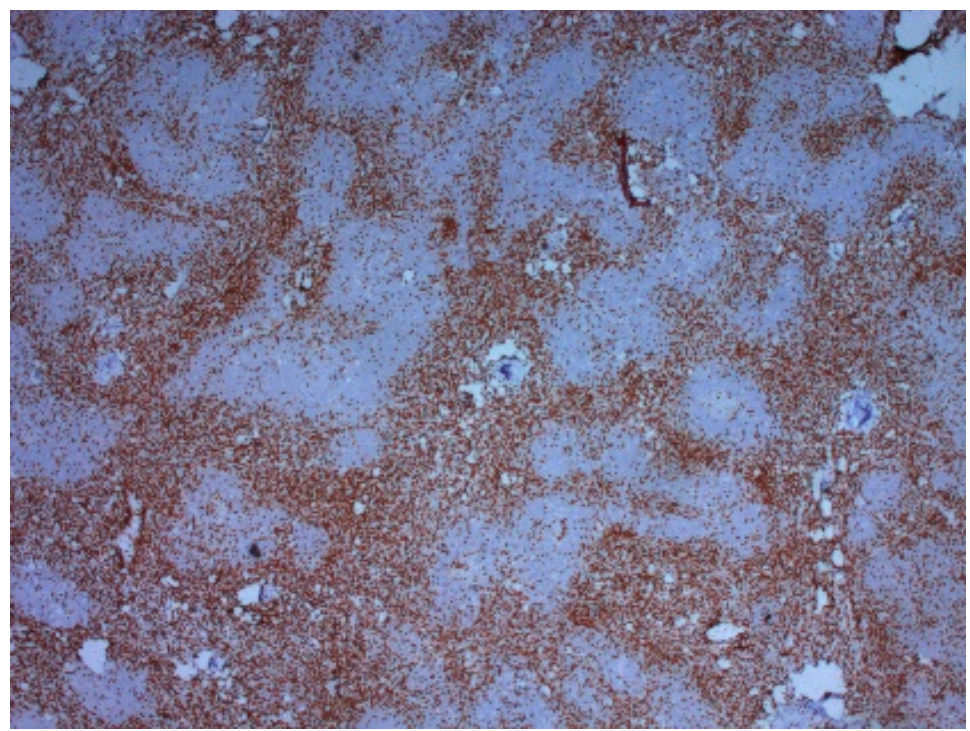

Figure 29. Histopathology CD3-interfollicular areas. 


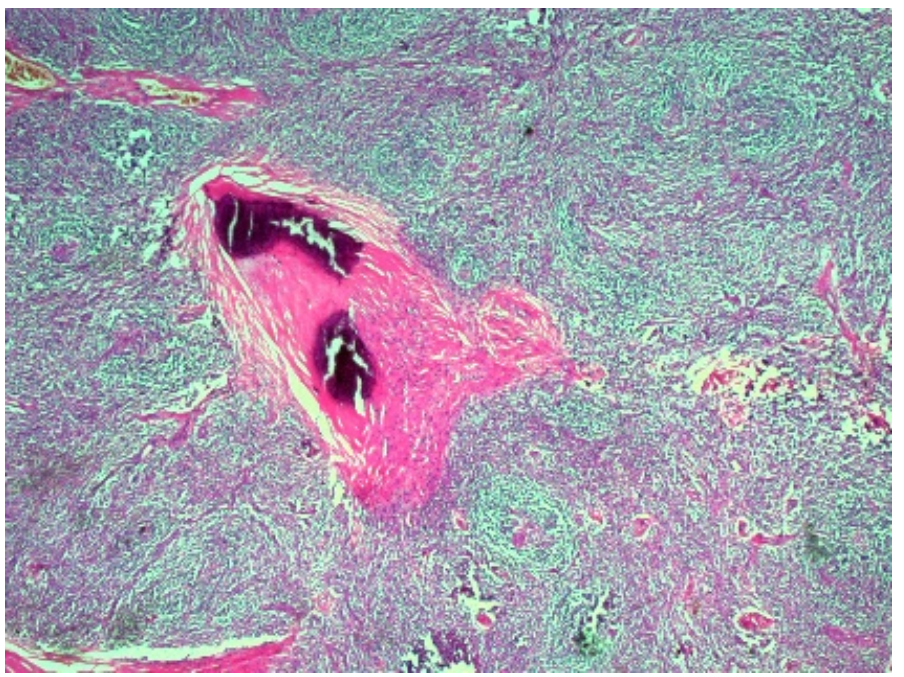

Figure 30. Histopathology calcification-H \& E staining.

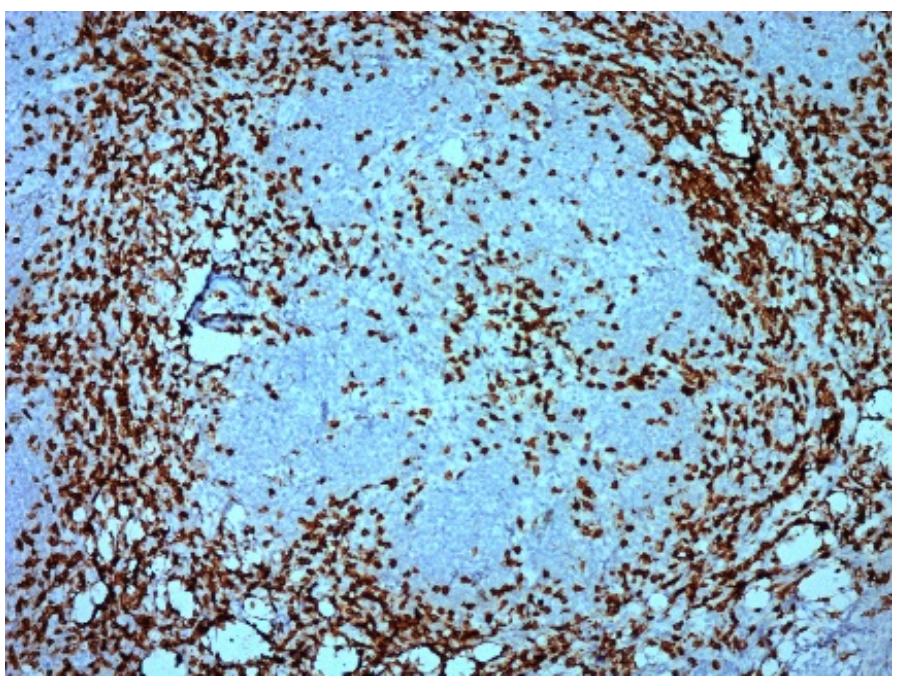

Figure 31. Histopathology CD3-interfollicular areas.

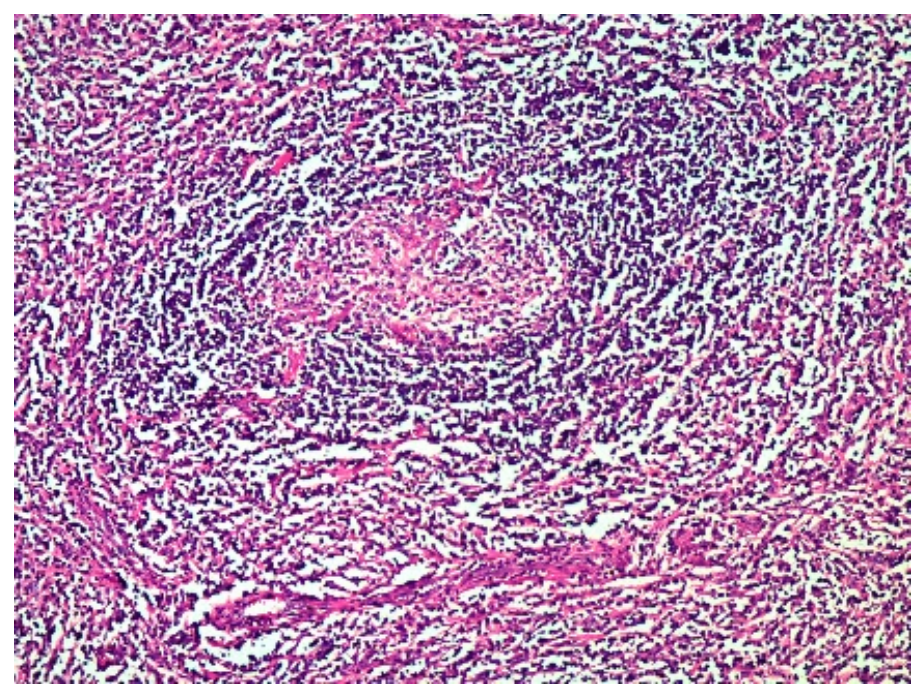

Figure 32. Histopathology concentric onion skin appearance. 


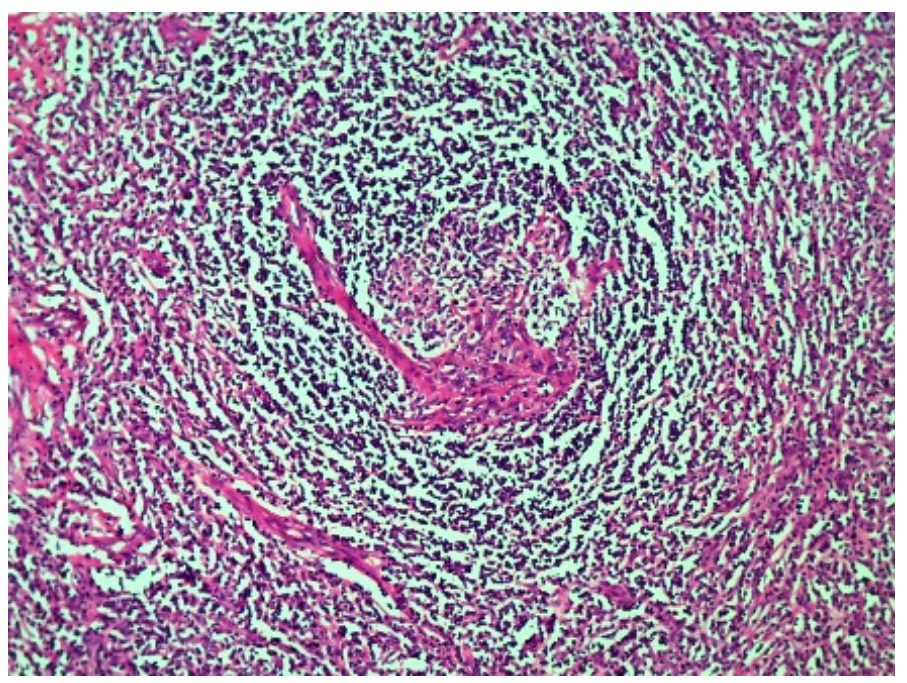

Figure 33. Histopathology onion skin appearnance.

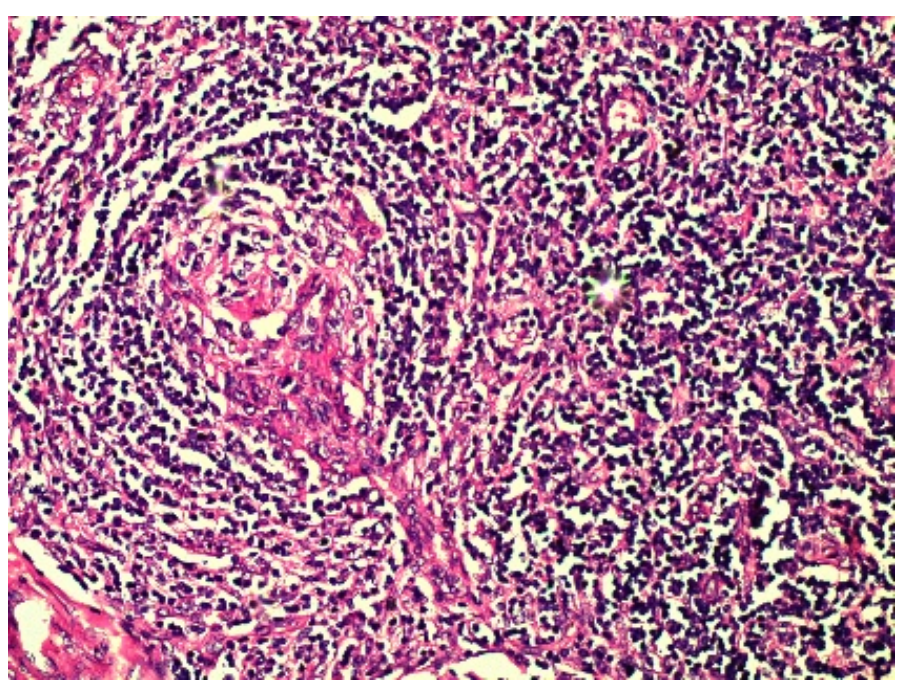

Figure 34. Histopathology lollipop appearance of follilce-H \& E 10×.

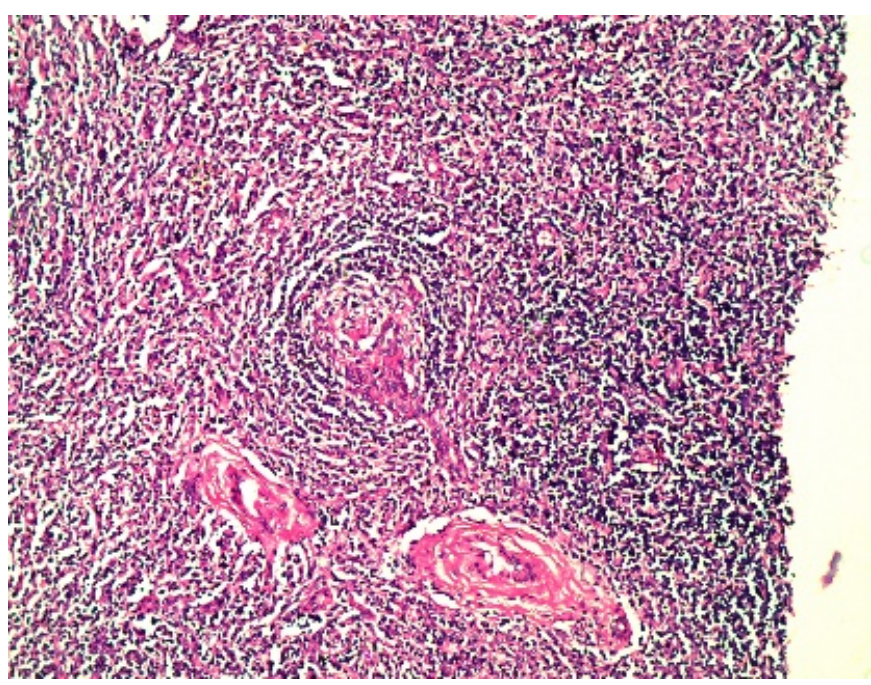

Figure 35. Histopathology lollipop follicle and hyalinsed vessel. 


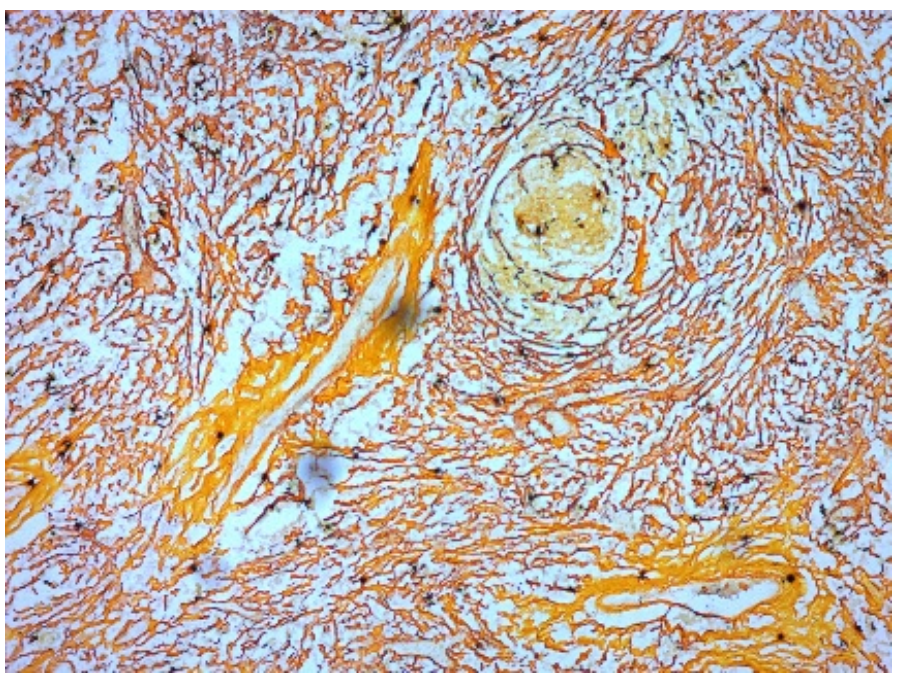

Figure 36. Histopathology Reticulin stain-lollipop appearance.

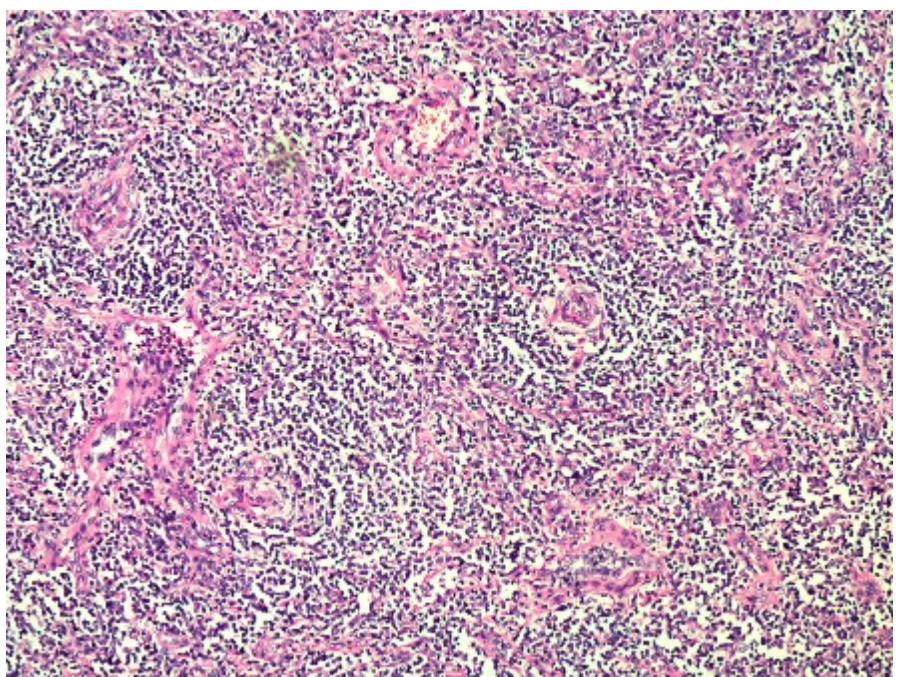

Figure 37. Histopathology increased high endothelial venules.

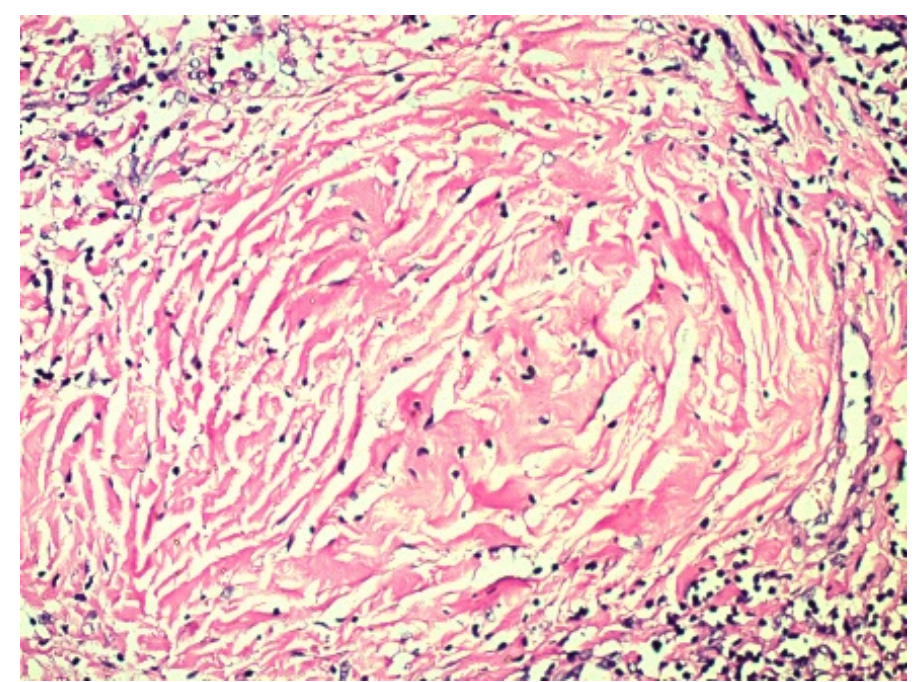

Figure 38. Histopathology hyalinized follicle-H \& E, 40×. 
Patient was discharged from the hospital on $2^{\text {nd }}$ post-operative day. Prophylactic antibiotics were given for 7 days. For glucose intolerance tab metformin in dose of $500 \mathrm{mg}$ OD was started and her blood sugar was monitored. Post-operative follow-up on day 8 and 1 month and $4^{\text {th }}$ month was uneventful. On day 14 and $4^{\text {th }}$ month of post-operative period, PET-CT scan reported no abnormal FDG avid lesion in primary operative bed, no evidence of pelvic or abdominal lymphadenopathy and no abnormal FDG avid osteosclerotic lesions in visualized bones.

\section{Discussion}

Castleman's disease $(\mathrm{CD})$ is a rare benign lymphoproliferative disorder. The disease is called as orphan disease as the incidence is 16 to $21-25 /$ million person years [1] [2]. In UCD (Unicentric Castleman's disease) single region lymph nodes are enlarged, such enlarged lymph node in pelvic retroperitoneal area is further rare. There are 15 cases reports pelvic retroperitoneal cases of UCD published in literature. This will be the such $16^{\text {th }}$ case published in literature and $3^{\text {rd }}$ treated by laparoscopic surgery [3]. Last such case published in Feb 2020 was operated in 2019 [3]. In the other case reports laparotomy was performed for surgical excision of pelvic retroperitoneal disease [4] [5].

UCD is more often commonly found in young age more in females aged 20 30 yrs. Patient can be asymptomatic or there are symptoms related to pressure effects on surrounding structures. The present case is the youngest case of pelvic lesion treated by laparoscopic excision. Previous 2 such laparoscopic excision reported was in 27 and 46 years of age. The youngest patient having pelvic retroperitoneal disease at the same site was of 12 years of age in which laparotomy was performed [6]. Ironically in all cases of laparoscopic surgery reported the size of the mass between $5-7 \mathrm{~cm} \mathrm{[3]} \mathrm{[4].} \mathrm{In} \mathrm{the} \mathrm{present} \mathrm{case,} \mathrm{the} \mathrm{patient} \mathrm{had}$ pelvic and lower abdominal pain because of the pressure effect of large lymph node. Laparoscopic excision of unicentric Castleman's has been reported for other sites in peritoneal cavity [7]. Castleman's disease should be included as one of the differential diagnosis points in female adnexal mass. The other mass in this area can be lymphoma, sarcoma, metastasis, neural tumour, and granulomatous disease [8]. The mass related to ovary at this site can be dermoid cyst, endometriotic cyst or ovarian abscess.

There are three histological variants of Castleman's disease described classic hyaline-vascular form usually found in UCD, the plasma cell type more seen in MCD (Multicentric Castleman's disease) type (9\% to $24 \%$ of UCD) and the plasmablastic cells or plasma cell CD more commonly seen in patients with MCD with HHV-8 infection. POEMS syndrome (Polyneuropathy, organomegaly, endocrinopathy, monoclonal gammopathy, and skin changes) and TAFRO syndrome (thrombocytopenia, anasarca, reticulin fibrosis of the bone marrow, renal dysfunction, and organomegaly) can be associated with MCD [9].

The histopathology of the excised mass was identical as angio follicular lym- 
phoid hyperplasia-Castleman's disease (Hyaline vascular type) [10].

Laparoscopic surgery should be offered in all such case of pelvic UCD around external iliac vessels as it provides more magnified view and helps in precise dissection and haemostasis as it was performed in this patient [3] [4]. Fibrosis is expected around such pelvic lesion. Careful dissection is mandatory to avoid incomplete resection and haemorrhage. Maryland type vessel sealer probe to perform surgery in present case is an effective dissector and vessel sealer as a single instrument in laparoscopic surgery. This avoids change of instruments and reduces time of surgery. While the both previous authors had used separate unipolar and bipolar instruments for performing the surgery. The pictures of surgery shared by the authors of laparoscopic surgery also appear almost similar. The consistency of the mass expressed was rubbery firm in the previous case reports while as in the present case it was firm too hard.

Surgical approach was most commonly applied for UCD at different locations and these patients had overall high survival rate. If the excisional surgery is unsuccessful the mortality remains high [3] [11].

There is a risk of excessive bleeding in surgery as the mass is vascular. In the present case, the estimated intraoperative blood loss was $10 \mathrm{cc}$.

As the lesions are vascular some authors have suggested pre-operative vascular embolization of the feeding vessels especially presence at odd locations [12].

The lesions in case of UCD are larger as compared to MCD [13]. In the present case also the lesion was large as $73 \times 49 \mathrm{~mm}$.

In incompletely excised mass with recurrence of symptoms, the patient will require treatment by chemotherapy [3]. This means a close follow up and additional treatment is required where the mass was not completely removed.

In case of nonresectable mass, radiotherapy is used to treat UCD with reasonable success [14] [15] [16].

Patients of MCD with elevated IL 6 levels have inflammation related symptoms as fever, night sweats, weight loss, generalized lymphadenopathy, hepatosplenomegaly, ascites, pericardial effusions, pleural effusions, peripheral edema, anaemia, glomerulonephritis and pemphigus. Depending upon the severity of the disease and HIV status patients of MCD are treated with single or multiple agent chemotherapy. Recombinant monoclonal antibody therapy to CD20 and IL-6 and its receptor and antiviral agents are also given as standard treatment [10] [17] [18] [19] [20]. Prognosis of HHV 8 positive MCD is good as compared to HHV 8 negative [21].

\section{Conclusions}

We now know more about the disease profile and pathogenesis of $\mathrm{CD}$ since its first diagnosis about 66 years back. MCD is less common than UCD. A high index of suspicion is required to diagnose these conditions as it is a rare disease. There are a limited number of retroperitoneal UCD reported in female pelvis. Other retroperitoneal mass in females can be ovarian tumor, endometriomas, 
lymphoma, sarcoma, metastasis, neural tumor and granulomatous disease.

In case of doubt in diagnosis excisional biopsy should be performed as it was done in this case. Castleman's disease should be included as differential diagnosis in female with pelvic mass.

Excisional surgery gives a good prognosis and survival in UCD. Considering the existing published data for the management on Unicentric Castleman's disease surgical resection appears to be the most effective treatment for resectable lesions. Laparoscopic excision is best suited for retroperitoneal pelvic unicentric Castleman's disease.

\section{Conflicts of Interest}

The authors declare no conflicts of interest regarding the publication of this paper.

\section{References}

[1] Munshi, N., Mehra, M., Van De Velde, H., Desai, A., Potluri, R. and Vermeulen, J. (2015) Use of a Claims Database to Characterize and Estimate the Incidence Rate for Castleman Disease. Leukemia \& Lymphoma, 56, 1252-1260.

https://doi.org/10.3109/10428194.2014.953145

[2] Simpson, D. (2018) Epidemiology of Castleman Disease. Hematology/ Oncology Clinics of North America, 32, 1-10. https://doi.org/10.1016/j.hoc.2017.09.001

[3] Nakata, K., et al., (2020) Laparoscopically Resected Castleman's Disease in the Pelvic Retroperitoneum: A Case Report. Molecular and Clinical Oncology, 12, 169-173. https://doi.org/10.3892/mco.2019.1963

[4] Lee, J.S., Paek, J.H., Lee, Y.H., Kong, T.W., Chang, S.J. and Ryu, H.S. (2015) Pelvic Castleman's Disease Presenting as an Adnexal Tumor in a Young Woman. Obstetrics \& Gynecology Science, 58, 323-326. https://doi.org/10.5468/ogs.2015.58.4.323

[5] Sato, A. (2013) Castleman's Disease in the Pelvic Retroperitoneum: A Case Report and Review of the Japanese Literature. International Journal of Surgery Case Reports, 4, 19-22. https://doi.org/10.1016/j.ijscr.2012.08.016

[6] Schelble, A.P. and Merritt, D.F. (2019) Pelvic Castleman's Disease Presenting as an Adnexal Mass in an Adolescent. Journal of Pediatric \& Adolescent Gynecology, 32, 86-89. https://doi.org/10.1016/j.jpag.2018.09.002

[7] Tarik, Z., Cimpean, S., Marechal, M.T., Cadiere, B., A Dieu Byabene, G. and Bez, M. (2019) Laparoscopic Management of a Unicentric Abdominal Mesenteric Localization of the Castleman Disease. EC Gastroenterology and Digestive System, 6, 673-677.

[8] Bonekamp, D., Horton, K.M., Hruban, R.H. and Fishman, E.K. (2011) Castleman Disease: The Great Mimic. Radiographics, 31, 1793-1807. https://doi.org/10.1148/rg.316115502

[9] Cronin, D.M.P. and Warnke, R.A. (2009) Castleman Disease: An Update on classification and the Spectrum of Associated Lesions. Advances in Anatomic Pathology, 16, 236-246. https://doi.org/10.1097/PAP.0b013e3181a9d4d3

[10] Chan, K.L., Lade, S., Prince, H.M. and Harrison, S.J. (2016) Update and New Approaches in the Treatment of Castleman Disease. Journal of Blood Medicine, 7, 145-158. https://doi.org/10.2147/JBM.S60514 
[11] Mitsos, S., Stamatopoulos, A., Patrini, D., George, R.S., Lawrence, D.R. and Panagiotopoulos, N. (2018) The Role of Surgical Resection in Unicentric Castleman's Disease: A Systematic Review. Advances in Respiratory Medicine, 86, 36-43. https://doi.org/10.5603/ARM.2018.0008

[12] Aydemir, B., Okay, T., Imamoglu, O., Sahin, S. and Dogusoy, I. (2010) Preoperative Embolization in Mediastinal Castleman's Disease. The Journal of Thoracic and Cardiovascular Surgery, 58, 496-498. https://doi.org/10.1055/s-0030-1250088

[13] Zhao, S., Wan, Y., Huang, Z.X., Song, B. and Yu, J.Q. (2019) Imaging and Clinical Features of Castleman Disease. Cancer Imaging, 19, Article No. 53. https://doi.org/10.1186/s40644-019-0238-0

[14] Li, Y.M., et al. (2011) Radiotherapy of Unicentric Mediastinal Castleman's Disease. Chinese Journal of Cancer, 30, 351-356. https://doi.org/10.5732/cjc.010.10402

[15] Kyu Noh, O., et al. (2013) Cases Report of Unicentric Castleman's Disease: Revisit of Radiotherapy Role. Radiation Oncology Journal, 31, 48-54. https://doi.org/10.3857/roj.2013.31.1.48

[16] Chronowski, G.M., Ha, C.S., Wilder, R.B., Cabanillas, F., Manning, J. and Cox, J.D. (2001) Treatment of Unicentric and Multicentric Castleman Disease and the Role of Radiotherapy. Cancer, 92, 670-676. https://doi.org/10.1002/1097-0142(20010801)92:3<670::AID-CNCR1369>3.0.CO;2-Q

[17] Kapriniotis, K., Lampridis, S., Mitsos, S., Patrini, D., Lawrence, D.R. and Panagiotopoulos, N. (2018) Biologic Agents in the Treatment of Multicentric Castleman Disease. Turkish Thoracic Journal, 19, 220-225.

https://doi.org/10.5152/TurkThoracJ.2018.18066

[18] Prakash, G., et al. (2016) Presentation and Outcome of Castleman's Disease in Immunocompetent Hosts. Indian Journal of Hematology and Blood Transfusion, 32, 468-474. https://doi.org/10.1007/s12288-015-0602-6

[19] Fajgenbaum, D.C. (2018) Novel Insights and Therapeutic Approaches in Idiopathic Multicentric Castleman Disease. Hematology, ASH Education Program, 2018, 318-325. https://doi.org/10.1182/asheducation-2018.1.318

[20] Van Rhee, F., Stone, K., Szmania, S., Barlogie, B. and Singh, Z. (2020) Castleman Disease in the 21st Century: An Update on Diagnosis, Assessment, and Therapy. Clinical Advances in Hematology and Oncology, 8, 486-498.

[21] Yu, L., et al. (2017) Clinical and Pathological Characteristics of HIV- and HHV-8-Negative Castleman Disease. Blood, 129, 1658-1668.

https://doi.org/10.1182/blood-2016-11-748855 